Article

\title{
Synthesis of Nanocrystalline Mg-Al Hydrotalcites in the Presence of Starch-the Effect on Structure and Composition
}

\author{
Alicja Michalik, Bogna D. Napruszewska, Anna Walczyk, Joanna Kryściak-Czerwenka, \\ Dorota Duraczyńska and Ewa M. Serwicka *(D)
}

Jerzy Haber Institute of Catalysis and Surface Chemistry, Niezapominajek 8, 30-239 Krakow, Poland; ncmichal@cyf-kr.edu.pl (A.M.); ncnaprus@cyf-kr.edu.pl (B.D.N.); ncawalczyk@cyf-kr.edu.pl (A.W.); nckrysci@cyf-kr.edu.pl (J.K.C.); ncduracz@cyf-kr.edu.pl (D.D.)

* Correspondence: ncserwic@cyf-kr.edu.pl; Tel.: +48-12-6395-118

Received: 9 December 2019; Accepted: 24 January 2020; Published: 29 January 2020

\begin{abstract}
The study describes the synthesis of $\mathrm{Mg}$-Al hydrotalcite (Ht) with the use of starch as a structure controlling biotemplate. Syntheses were carried out at room temperature, by co-precipitation at $\mathrm{pH}=10$. The investigated synthesis parameters included the nature of the precipitating agent $\left(\mathrm{NaOH} / \mathrm{Na}_{2} \mathrm{CO}_{3}\right.$ or $\left.\mathrm{NH}_{3} \mathrm{aq} /\left(\mathrm{NH}_{4}\right)_{2} \mathrm{CO}_{3}\right)$, the nature of starch (potato, corn and cassava), the method of starch addition to reagents, the method of drying and the effect of washing. The materials were examined with X-ray diffraction, scanning electron microscopy/energy dispersive X-ray spectroscopy and infrared spectroscopy. The data show that synthesis of Ht materials in the presence of starch, with use of the ammonia-based precipitant, enabled preparation of nanocrystalline $\mathrm{Ht}$ with very fine $(<50 \mathrm{~nm})$ particle size. All investigated starches had a similar effect on the crystallinity and the grain size of $\mathrm{Ht}$ precipitates. Ht with the smallest nanocrystals was obtained when starch was present in all solutions used for synthesis, and the final product subjected to freeze drying. Washing with water was found to enhance recrystallization and exchange of nitrates for carbonates. Infrared spectra showed that an interaction exists between the biopolymer template and the $\mathrm{Ht}$ particles, resulting in a higher degree of order within the Ht-adhering starch component.
\end{abstract}

Keywords: hydrotalcite; layered double hydroxide; biotemplate; starch; nanoparticles; crystallinity

\section{Introduction}

Synthetic hydrotalcite-like materials $(\mathrm{Ht})$, related to the naturally occurring mineral of chemical composition $\left[\left(\mathrm{Mg}_{0.75} \mathrm{Al}_{0.25}\right)(\mathrm{OH})_{2}\right]\left(\mathrm{CO}_{3}\right)_{0.125} \cdot 0.5 \mathrm{H}_{2} \mathrm{O}$, are also referred to as layered double hydroxides (LDHs), or anionic clays [1]. The layered Ht structure is extremely flexible and may accommodate a number of divalent $\mathrm{M}^{2+}$ and trivalent $\mathrm{M}^{3+}$ cations other than $\mathrm{Mg}^{2+}$ and $\mathrm{Al}^{3+}$, in a variable atomic ratio, as well as anions other than carbonate. In consequence, the $\mathrm{Ht}$ materials are described by the general formula $\left[\mathrm{M}^{2+}{ }_{1-\mathrm{x}} \mathrm{M}^{3+}{ }_{\mathrm{x}}(\mathrm{OH})_{2}\right]^{\mathrm{x}+}\left(\mathrm{A}^{\mathrm{n}-}{ }_{\mathrm{x} / \mathrm{n}}\right) \cdot \mathrm{mH}_{2} \mathrm{O}$, where $\mathrm{M}^{2+}$ and $\mathrm{M}^{3+}$ are the elements forming the hydroxide layer, $\mathrm{A}^{\mathrm{n}-}$ is the interlayer anion compensating the layer charge, and $\mathrm{H}_{2} \mathrm{O}$ refers to the interlayer water. Ht materials find numerous applications as catalysts, adsorbents, medicines and medicine carriers, polymer fillers, etc. [1-9]. Of particular importance are nanostructural forms of $\mathrm{Ht}$ with controllable particle size, morphology, crystallinity and texture. However, although $\mathrm{Ht}$ have the advantage of being easily prepared in laboratory, the conventional methods of their synthesis, e.g., co-precipitation at a constant $\mathrm{pH}$, yield generally precipitates composed of aggregated particles, and offer only limited control over textural properties. Among advanced synthetic procedures developed with aim to prepare $\mathrm{Ht}$ materials with carefully designed nanostructure, the most 
promising ones are those based on the concept of structure templating [7]. The advantages of templating strategy are good reproducibility, possibility of large-scale synthesis and abundance of viable structure-directing templates.

Due to the increasing awareness towards biocompatibility of synthetic procedures, a new trend in template mediated synthesis of Ht materials emerged in the last few years, based on the use of naturally occurring biomaterials for engineering of novel nanostructures [7]. The biotemplating approach takes advantage of intricate morphology, hierarchical inner structure and surface functionalities of natural materials. The method is considered particularly attractive owing to the low cost, renewable nature, biodegradable character, and environmental compatibility of natural reagents. A literature search shows that synthesis of $\mathrm{Ht}$ with the use of sacrificial biotemplates is a very recent tendency, with research concentrating so far on the hard templating syntheses, in which the nanostructure of rigid biomaterials was replicated in the final $\mathrm{Ht}$ product [10-19]. In most works cellulosic polymers of various provenience have been used in the capacity of sacrificial biotemplates. In such a way formation of biomorphic hierarchical $\mathrm{Mg}-\mathrm{Al}, \mathrm{Zn}-\mathrm{Al}$ and $\mathrm{Ni}-\mathrm{Al} \mathrm{Ht}$ was achieved, the materials proving to be excellent adsorbents of a variety of substances, including bovine serum albumin, oil, dyes and antibiotics [11,13-16,18]. Zhang et al. [12] demonstrated that advanced $\mathrm{Zn}-\mathrm{Al} \mathrm{Ht} / \mathrm{Al}_{2} \mathrm{O}_{3}$ composites with tunable compositions and micro/nanostructures could be grown by structure replication of cellulose fibers. In some cases complex biological nanoarchitectures, such as those provided by pine pollen or surface of legume, were used, and resulted in hierarchical nanostructures with improved photocatalytic and/or catalytic performance $[10,17,19]$.

In contrast, the use of sacrificial soft biotemplates, i.e., deformable systems based on organic molecules or supramolecules, remains, as yet, a virtually unexplored area, with only a couple of recent works addressing this issue [20,21], despite the known ability of $\mathrm{Ht}$ to form nanocomposites with soft biopolymers [22]. There is no doubt, however, that this methodology will soon gain on importance, since soft biotemplating procedures proved fruitful in the syntheses of nanostructured metal oxides [23-26].

The present work aims at getting deeper insight into the application of starch as a soft templating agent for the synthesis of nanostructured Ht materials. Nanocrystalline Ht solids can be obtained, for instance, from water-in-oil microemulsions, but the syntheses are very laborious and difficult to upscale [27-30]. The attractive feature of starch biopolymers is their "green" character, abundant availability, low cost, and facile gelation in aqueous medium [31]. Starch is a mixture of homopolymers of $\alpha$-D-glucose: amylose (linear) and amylopectin (branched), and typically forms granules, which, depending on the biological origin, vary in shape, size, structure, and chemical composition. Properties of starch can be modified by physical methods, e.g., thermal treatment in various solvents, ultrasonication, microwave treatment, or chemically, by introducing new functional groups bringing about distinctive changes in the physicochemical properties of the polymer. All these features render starch templates particularly appealing for the purpose of materials design. This study concentrates on the effect brought about by the use of starch template, under various synthetic conditions, on the structural and compositional properties of prepared $\mathrm{Mg}-\mathrm{Al} \mathrm{Ht}$ materials. Alkali hydroxides in combination with appropriate alkali carbonates are the most frequently used precipitating agents for the synthesis of carbonate forms of $\mathrm{Ht}$ [1]. However, the resulting products usually contain alkali contaminants, which may be detrimental for some Ht applications. For instance, when used as solid base catalysts in biodiesel production, such materials may release alkali ions to the reaction mixture, thereby contaminating the product and diminishing the advantage of a heterogeneous versus homogeneous catalysis [32]. In such cases the use of an alkali-free synthetic procedure, e.g., by replacing alkali reagents with ammonia-based ones, is advised [33]. This aspect is a focus of the present study, because alkali-free synthesis enables direct thermal treatment of the as received dried Ht/starch mixtures. 


\section{Materials and Methods}

Synthesis of $\mathrm{Ht}$ with the intended $\mathrm{Mg} / \mathrm{Al}$ ratio equal to 3 was carried out at room temperature, by co-precipitation at $\mathrm{pH}=10$, using $1 \mathrm{M}$ aqueous solution of $\mathrm{Mg}$ and $\mathrm{Al}$ nitrates as the source of structure-forming cations, $7.5 \% \mathrm{NaOH}$ or $10 \% \mathrm{NH}_{3}$ aqueous solutions as precipitating agents, and $\mathrm{Na}_{2} \mathrm{CO}_{3}$ or $\left(\mathrm{NH}_{4}\right)_{2} \mathrm{CO}_{3}$, as sources of carbonate anions, respectively. All chemicals were of p.a. purity, provided by $\mathrm{POCH}$, Poland. The materials are further referred to as $\mathrm{Ht}^{\mathrm{NaOH}}$ and $\mathrm{Ht}^{\mathrm{NH} 3}$. Syntheses in the presence of starch template were carried out by dissolving selected reagents in the gelatinized aqueous solution of starch prepared by heating $0.2 \mathrm{wt} . \%$ starch suspension in water at $95^{\circ} \mathrm{C}$ for $3 \mathrm{~h}$. Commercial potato (PPZ Trzemeszno, Trzemeszno, Poland), corn (Melvit SA, Warszawa, Poland), and cassava (Bio Planet SA, Leszno, Poland) starches, referred to as POS, COS, and CAS, were investigated.

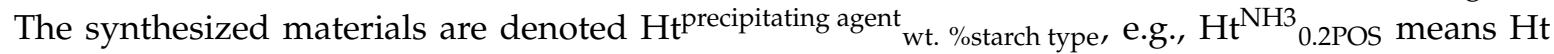
precipitated with ammonia-based reactants, in the presence of $0.2 \mathrm{wt} . \%$ POS gel. The precipitates were separated from the mother liquor by centrifugation, and dried in a drying box at $50{ }^{\circ} \mathrm{C}$ without washing. In order to check on the effect of method of drying, a selected as received sample was divided into two parts, of which one was dried in a drying box at $50{ }^{\circ} \mathrm{C}$, the other, after solidification in liquid nitrogen, was freeze-dried in a CHRIST freeze dryer Alpha 1-4/LD. The effect of washing was studied by subjecting the as received freeze-dried $\mathrm{Ht}^{\mathrm{NH} 3}{ }_{0.2 \mathrm{POS}}$ precipitate to three washing/centrifugation cycles with distilled, not decarbonated water, of temperature $0,25,50$ or $80^{\circ} \mathrm{C}$, followed by freeze drying of the resulting slurry.

X-ray diffraction (XRD) patterns were recorded using X'Pert PRO MPD (PANalytical, Almelo, The Netherlands) diffractometer with $\mathrm{CuK} \alpha$ radiation $(40 \mathrm{kV}, 30 \mathrm{~mA})$ selected by a nickel monochromator in the diffraction beam, with a step size $0.05^{\circ}$. Crystal sizes (the sizes of coherently scattering domains) of the $\mathrm{Ht}$ materials in the $c$ and $a$ direction of the unit cell, corresponding to the plate-like crystal thickness and lateral dimension, were estimated by analyzing the broadening of (003) and (110) reflections with Scherrer equation $D_{h k l}=K \lambda / \beta \cos \theta\left(D_{h k l}\right.$-coherently scattering domain in the direction perpendicular to the (hkl) plane; $\mathrm{K}$ - shape factor, usually assumed $0.9, \lambda$-incident ray wavelength; $\theta$-Bragg diffraction angle and $\beta$-full width at half maximum of the (hkl) reflection, after correcting for the instrumental broadening), using the X'Pert High Score software (version 3.0, PANalytical, Almelo, The Netherlands). It must be noted that, in general, lattice disorder and/or strain, caused by, e.g., mechanical activation, if present, would also contribute to line broadening. Therefore the actual dimensions of coherently scattering domains may be somewhat larger than those obtained with the Scherrer estimate, but the latter serve well as indicators for comparative study of crystallinity trends. Whenever possible, the deconvolution of superimposed XRD reflexes was carried out with aid of the $X^{\prime}$ Pert High Score software. The uncertainty in calculation of the lattice parameters is $<0.05 \%$ of the determined value, the error of $\mathrm{D}_{\mathrm{hkl}}$ determination about $10 \%$.

Scanning electron microscopy-energy dispersive X-ray spectroscopy (SEM/EDS) analysis was carried out with aid of JEOL JSM-7500F microscope (JEOL, Tokyo, Japan) coupled with INCA PentaFetx3 EDS (Oxford Instruments, Abingdon, UK) system. SEM images were recorded for the uncoated samples deposited on 200 Mesh copper grids covered with carbon support film.

Fourier transform infrared (FTIR) absorption spectra in middle infrared were recorded using transmission mode with Nicolet 6700 spectrometer (Thermo Scientific, Madison, WI, USA), in the $4000-400 \mathrm{~cm}^{-1}$ range. Samples were prepared as $\mathrm{KBr}$ pellets. 64 scans at $2 \mathrm{~cm}^{-1}$ resolution were taken for each sample.

\section{Results and Discussion}

For reasons indicated in the Introduction, the research presented in this work concentrated on the use of $\mathrm{NH}_{3}$ aq and $\left(\mathrm{NH}_{4}\right)_{2} \mathrm{CO}_{3}$ as precipitating agents, but for the purpose of comparison, some $\mathrm{Mg}$ - $\mathrm{Al}$ $\mathrm{Ht}$ samples were also synthesized using the Na-based reagents. The data in Table 1 shows that the Ht materials obtained with $\mathrm{NH}_{3} \mathrm{aq} /\left(\mathrm{NH}_{4}\right)_{2} \mathrm{CO}_{3}$ reagents tended to display a somewhat lower $\mathrm{Mg} / \mathrm{Al}$ ratio than those prepared with the use of $\mathrm{NaOH} / \mathrm{Na}_{2} \mathrm{CO}_{3}$, which agrees with the previous report [34]. 
Table 1. The effect of the precipitating agent and of the nature of starch on XRD determined $\mathrm{d}_{003}$ and $\mathrm{d}_{110}$ interplanar spacings, and $\mathrm{D}_{003}$ and $\mathrm{D}_{110}$ crystal sizes; EDS determined $\mathrm{Mg} / \mathrm{Al}$ ratio.

\begin{tabular}{cccccc}
\hline \multirow{2}{*}{ Sample } & \multicolumn{2}{c}{ Interplanar Spacing $(\mathbf{n m})$} & \multicolumn{2}{c}{ Crystal Size (nm) } & \multirow{2}{*}{$\mathbf{M g} / \mathbf{A l}$} \\
\cline { 2 - 4 } & $\mathbf{d}_{\mathbf{0 0 3}}$ & $\mathbf{d}_{\mathbf{1 1 0}}$ & $\mathbf{D}_{\mathbf{0 0 3}}$ & $\mathbf{D}_{\mathbf{1 1 0}}$ & \\
\hline $\mathrm{Ht}^{\mathrm{NaOH}}$ & 0.780 & 0.1532 & 8.5 & 16.4 & 2.86 \\
$\mathrm{Ht}^{\mathrm{NaOH}}{ }_{0.2 \mathrm{POS}}$ & 0.785 & 0.1533 & 7.0 & 12.6 & 2.92 \\
$\mathrm{Ht}^{\mathrm{NH} 3}$ & 0.770 & 0.1526 & 7.2 & 14.7 & 2.59 \\
$\mathrm{Ht}^{\mathrm{NH}}{ }_{0.2 \mathrm{POS}}$ & 0.842 & n.d. & 3.3 & n.d. & 2.80 \\
$\mathrm{Ht}^{\mathrm{NH}}{ }_{0.2 \mathrm{COS}}$ & 0.836 & n.d. & 4.1 & n.d. & 2.77 \\
$\mathrm{Ht}^{\mathrm{NH} 3}{ }_{0.2 \mathrm{CAS}}$ & 0.847 & n.d & 3.6 & n.d & 2.68 \\
\hline
\end{tabular}

Figure 1 shows the XRD patterns of $\mathrm{Ht}^{\mathrm{NaOH}}$ and $\mathrm{Ht}^{\mathrm{NH} 3}$ materials obtained by the standard co-precipitation, and of the appropriate $\mathrm{Ht} / \mathrm{starch}$ composites prepared with the use $0.2 \mathrm{wt} . \%$ aqueous solution of POS gel instead of pure water, for preparation of all reagents. The diffractograms of $\mathrm{Ht}^{\mathrm{NaOH}}$ and $\mathrm{Ht}^{\mathrm{NH} 3}$ samples are characteristic of a carbonate form of Ht-like structure, and the appropriate indexes of XRD reflections are given (ICSD ref. code 086655 ). The data on the $\mathrm{d}_{003}$ and $\mathrm{d}_{110}$ interplanar distances, and the crystal sizes along $(003)\left(\mathrm{D}_{003}\right)$ and $(110)\left(\mathrm{D}_{110}\right)$ directions are listed in Table 1 . In the case of samples prepared in the presence of starch with $\mathrm{NH}_{3}$ aq and $\left(\mathrm{NH}_{4}\right)_{2} \mathrm{CO}_{3}$ the (110) and (113) reflections are broadened and overlap, making determination of $\mathrm{d}_{110}$ and $\mathrm{D}_{110}$ parameters impossible. It is apparent that the nature of the precipitating agent impacts $\mathrm{Ht}$ crystallinity, and the use of $\mathrm{NaOH}$ yields more crystalline materials, both in the absence and in the presence of starch.

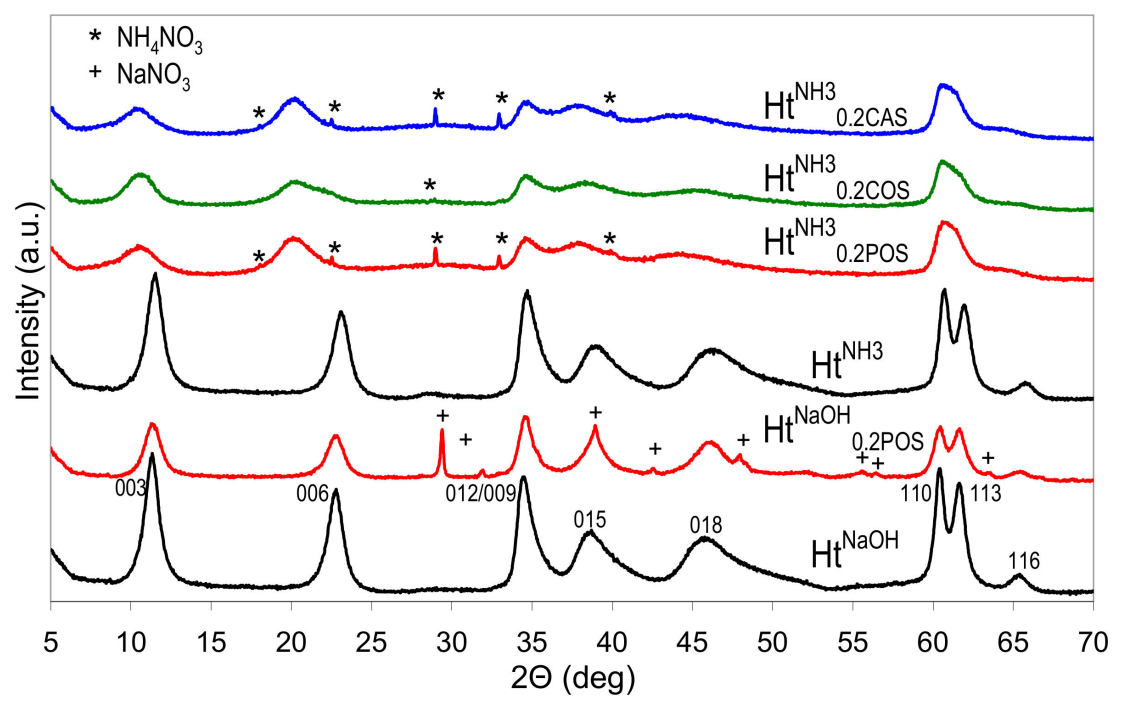

Figure 1. X-ray diffraction (XRD) patterns of $\mathrm{Ht}$ materials obtained with the use of different precipitating agents and in the presence or absence of various starches.

In all cases syntheses carried out in the presence of starches result in materials with lower crystallinity than that of the appropriate reference prepared in the standard manner. In the adopted synthetic conditions, the effect is practically independent on the nature of used starch. Depending on the precipitant, the samples contain some $\mathrm{NaNO}_{3}$ or $\mathrm{NH}_{4} \mathrm{NO}_{3}$ impurity. Noteworthy, all $\mathrm{Ht}$ prepared in the presence of starches and precipitated with $\mathrm{NH}_{3}$ aq are characterized by $\mathrm{d}_{003}$ values distinctly higher $(0.836-0.847 \mathrm{~nm})$ than those found in all other samples $(0.770-0.785 \mathrm{~nm})$. The basal spacing represents the sum of the layer and the interlayer thickness, and, therefore, is related to the size and orientation of charge balancing interlayer anions. The former values were closer to $\mathrm{d}_{003}$ characteristic of nitrate forms of $\mathrm{Ht}$, while the latter point to the formation of $\mathrm{Ht}$ with carbonates in the interlayer [1]. Certain asymmetry of (001) reflections visible in the XRD pattern of Ht synthesized 
in the presence of corn starch shows that the material was not quite homogeneous and part of the precipitate contains interlayer carbonate. Nevertheless, the predominance of the $\mathrm{d}_{003}$ around $0.84 \mathrm{~nm}$ indicates that, when $\mathrm{NH}_{3}$ aq was employed as a precipitating agent, the presence of starch hindered the formation of carbonates despite the well known affinity of the hydrotalcite structures with $\mathrm{Mg} / \mathrm{Al} \leq 3$ to intercalate carbonates as compensating anions [35]. It is known that, in the absence of intentionally added carbonate reagent, the use of ammonia precipitant, instead of $\mathrm{NaOH}$, prevents intercalation of adventitious carbonate from atmospheric $\mathrm{CO}_{2}$ source and favors intercalation of nitrate [36]. In view of the much lower dissociation constant of ammonium carbonate vs. sodium carbonate, the effect has been attributed to the enhanced association of ammonium with carbonate, which limits availability of $\mathrm{CO}_{3}{ }^{2-}$ in solution, and prevents its intercalation [35]. However, the use of $\mathrm{NH}_{3}$ aq in the presence of $\left(\mathrm{NH}_{4}\right)_{2} \mathrm{CO}_{3}$ reagent does lead to the formation of predominantly carbonate form of $\mathrm{Ht}$ [37]. Findings of this study show, for the first time, that the preferential formation of nitrate-containing $\mathrm{Ht}$ may be achieved even in the presence of ammonium carbonate, provided a biopolymer is added to the solutions of ammonium reagents used for the synthesis. We tentatively attributed this phenomenon to the increased viscosity of the reaction medium, which favors topotactic intercalation of nitrate anions, introduced together with the layer forming cations, rather than reaction with carbonates, which have to diffuse to the site of Ht nucleation from further distance.

High resolution SEM analysis of Ht materials prepared in the standard manner and in the presence of starch reveals that the latter procedure has a significant impact on the Ht grain morphology. The effect is illustrated in Figure 2, which compares the images of materials, whose XRD patterns are shown in Figure 1. It is obvious that starch-containing environment exerts spatial restrictions on the formation of Ht grains, and results, in the case of ammonia-based synthesis, in particles of ca. 30-50 nm diameter, while Ht obtained in the absence of a biopolymer, consists of much larger platelets, with lateral dimension of several tenth micron order. The plate-like morphology is preserved in all synthesized materials. Notably, the observed effect of particle diminution parallels the trend observed for samples crystallinity, although particle size was always much larger than the size of the relevant coherently scattering domain. In particular, the use of a biopolymer template together with $\mathrm{NH}_{3} \mathrm{aq} /\left(\mathrm{NH}_{4}\right)_{2} \mathrm{CO}_{3}$ precipitating agent yielded finer nanoparticles than those produced with $\mathrm{NaOH} / \mathrm{Na}_{2} \mathrm{CO}_{3}$.

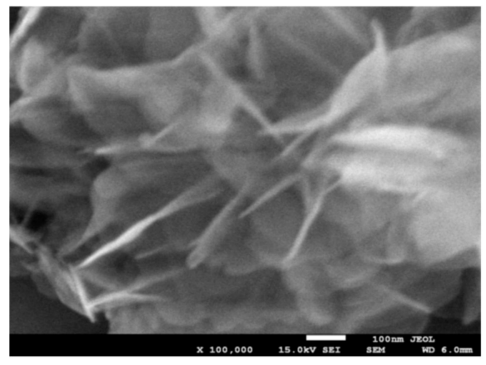

(a)

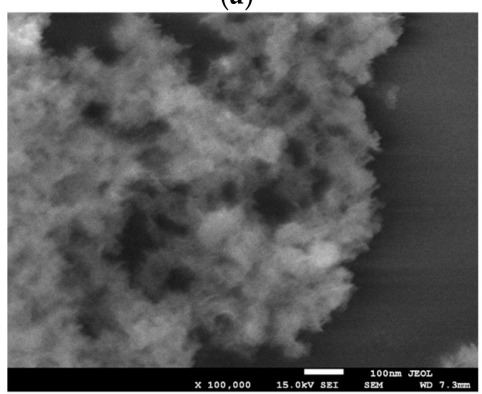

(d)

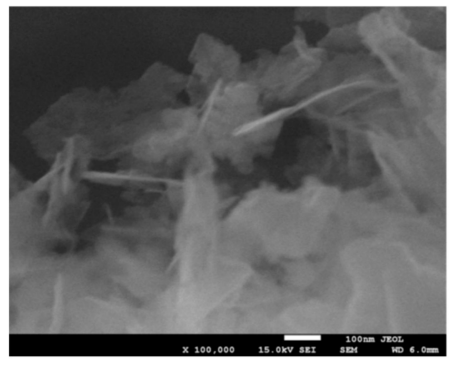

(b)

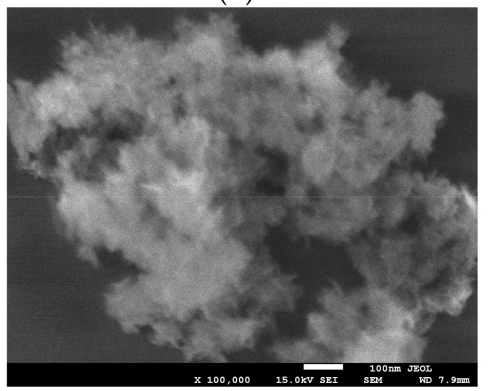

(e)

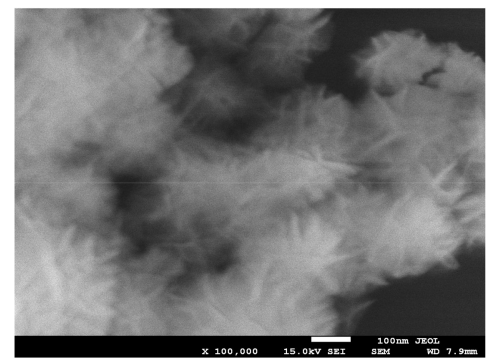

(c)

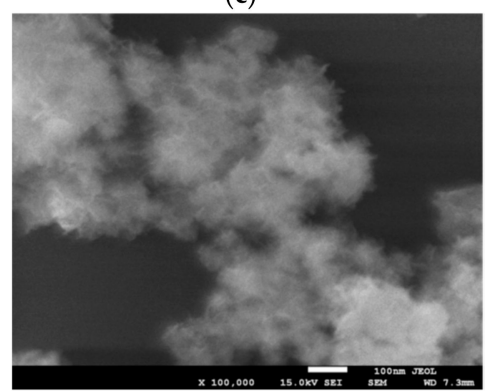

(f)

Figure 2. SEM images of $\mathrm{Ht}$ materials obtained with the use of different precipitating agents and in the presence or absence of various starches: (a) $\mathrm{Ht}^{\mathrm{NaOH}}$; (b) $\mathrm{Ht}^{\mathrm{NH}}$; (c) $\mathrm{Ht}^{\mathrm{NaOH}}{ }_{0.2 \mathrm{POS}}$; (d) $\mathrm{Ht}^{\mathrm{NH}}{ }_{0.2 \mathrm{POS}}$; (e) $\mathrm{Ht}^{\mathrm{NH} 3}{ }_{0.2 \mathrm{COS}}$ and (f) $\mathrm{Ht}^{\mathrm{NH} 3}{ }_{0.2 \mathrm{CAs}}$. Magnification $\times 100,000$. 
A preparative procedure of $\mathrm{Ht}^{\mathrm{NH} 3}{ }_{0.2 \mathrm{POS}}$ sample was chosen for studying the effect of the manner of starch addition (all reagents vs. selected ones), of the method of drying (drying box vs. freeze drier) and of introducing the stage of washing of the as received material, on the properties of the final product. XRD patterns presented in Figure 3 and calculated crystal sizes in Table 2 show that to maximize the nanocrystalline character of $\mathrm{Ht}$ it was important that all reagents used for the synthesis were prepared in starch solution. The presence of starch in only selected reagents did reduce the crystal size with respect to that of the reference $\mathrm{Ht}^{\mathrm{NH} 3}$, but clearly to a lesser degree. Another important factor determining the structural features of synthesized Ht samples was the manner of drying. Freeze-drying was clearly the preferred method for achieving the possibly low Ht crystal size, because it helped to preserve the as-received crystallinity, while during conventional drying a degree of recrystallization occurred (Figure 3, Table 2). Moreover, the $\mathrm{d}_{003}$ basal spacings of freeze-dried samples were consistently slightly higher than those of their counterparts dried in a conventional manner. This indicates that during time spent by the wet cake in a drying box a degree of Ht carbonation occurs.

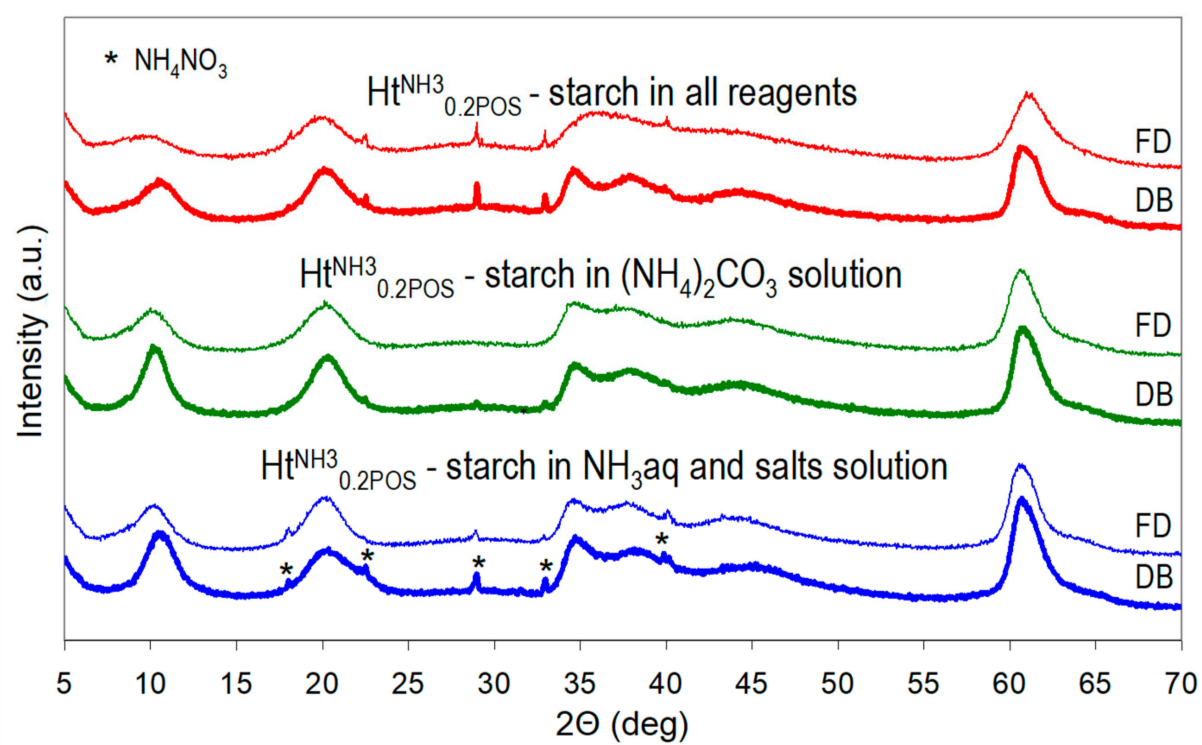

Figure 3. Impact of the method of starch addition (to all reagents, only to $\left(\mathrm{NH}_{4}\right)_{2} \mathrm{CO}_{3}$, or to $\mathrm{NH}_{3} \mathrm{aq}+$ salt solutions) and of the method of drying (drying box-DB or freeze-drier-FD) on XRD patterns of $\mathrm{HT}^{\mathrm{NH} 3}{ }_{0.2 \mathrm{PO}}$.

Table 2. The effect of the method of starch addition and of the method of drying on XRD determined d003 interplanar spacings, and $\mathrm{D}_{003}$ crystal sizes.

\begin{tabular}{ccccc}
\hline \multirow{2}{*}{ Sample } & \multicolumn{2}{c}{$\mathrm{d}_{003}$ Interplanar Spacing $(\mathrm{nm})$} & \multicolumn{2}{c}{$\mathrm{D}_{\mathbf{0 0 3}}$ Crystal Size $(\mathrm{nm})$} \\
\cline { 2 - 5 } & Drying Box & Freeze-drier & Drying Box & Freeze-drier \\
\hline $\begin{array}{c}\mathrm{Ht}^{\mathrm{NH} 3}{ }_{0.2 \mathrm{POS}} \\
\text { starch in all reagents }\end{array}$ & 0.842 & 0.897 & 3.3 & 2.8 \\
$\begin{array}{c}\mathrm{Ht}^{\mathrm{NH}}{ }_{0.2 \mathrm{POS}} \\
\text { starch in }\left(\mathrm{NH}_{4}\right)_{2} \mathrm{CO}_{3} \text { solution }\end{array}$ & 0.862 & 0.877 & 5.0 & 3.5 \\
$\begin{array}{c}\mathrm{Ht}^{\mathrm{NH} 3}{ }_{0.2 \mathrm{POS}} \\
\text { starch in } \mathrm{NH}_{4} \text { aq and in salts solution }\end{array}$ & 0.834 & 0.872 & 4.1 & 3.8 \\
\hline
\end{tabular}

As stated earlier, if the $\mathrm{Ht}$ materials prepared in the presence of starch were precipitated with $\mathrm{NH}_{3} \mathrm{aq}$, the washing of the as received samples in not necessary, because both starch and ammonium nitrate impurity will be removed during calcination. However, when the synthesis aims at preparation of uncalcined Ht samples, then a washing step has to be included in the preparative procedure, in order to obtain pure Ht phase. The starch polymer present in the as received precipitate is water soluble, hence it may be removed by washing with distilled water. The as received freeze-dried $\mathrm{Ht}^{\mathrm{NH} 3}{ }_{0.2 \mathrm{POS}}$ sample, with the lowest observed crystallinity, has been chosen to study the possible effect of washing. 
The sample has been subjected to washing with distilled water at various temperatures. The XRD patterns of the obtained materials are presented in Figure 4, while the calculated interplanar spacings, and crystal sizes are shown in Table 3.

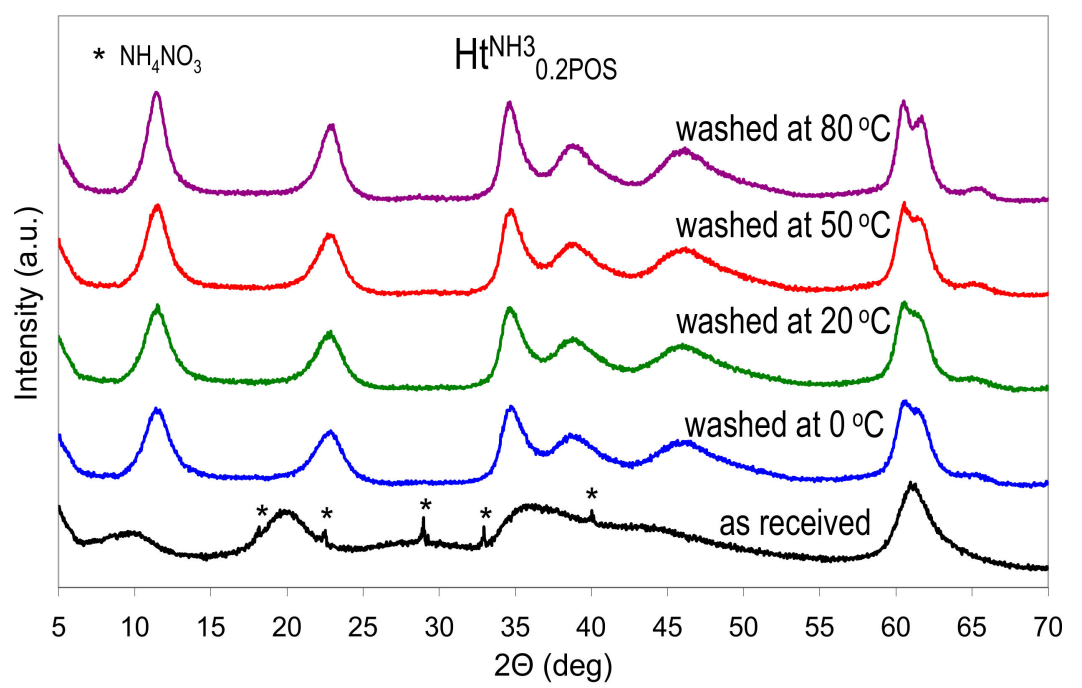

Figure 4. Structural changes in the $\mathrm{Ht}^{\mathrm{NH} 3}{ }_{0.2 \mathrm{PO}}$ sample upon washing with water at different temperatures. All materials freeze dried.

Table 3. The effect of washing with water on XRD determined $d_{003}$ and $d_{110}$ interplanar spacings, and $\mathrm{D}_{003}$ and $\mathrm{D}_{110}$ crystal sizes of freeze-fried $\mathrm{Ht}^{\mathrm{NH}}{ }_{0.2 \mathrm{POS}}$ sample.

\begin{tabular}{ccccc}
\hline Sample & \multicolumn{2}{c}{ Interplanar Spacing $(\mathbf{n m})$} & \multicolumn{2}{c}{ Crystal Size $(\mathbf{n m})$} \\
\cline { 2 - 5 } & $\mathbf{d}_{003}$ & $\mathbf{d}_{\mathbf{1 1 0}}$ & $\mathbf{D}_{003}$ & $\mathbf{D}_{\mathbf{1 1 0}}$ \\
\hline $\begin{array}{c}\mathrm{Ht}^{\mathrm{NH} 3}{ }_{0.2 \mathrm{POS}} \\
\text { as received }\end{array}$ & 0.897 & n.d. & 2.8 & n.d. \\
$\begin{array}{c}\mathrm{Ht} \mathrm{NH}^{\mathrm{NH}}{ }_{0.2 \mathrm{POS}} \\
\text { washed at } 0{ }^{\circ} \mathrm{C}\end{array}$ & 0.770 & 0.1530 & 4.2 & 8.4 \\
$\begin{array}{c}\mathrm{Ht} \mathrm{NH}_{0.2 \mathrm{POS}} \\
\text { washed at } 20^{\circ} \mathrm{C}\end{array}$ & 0.769 & 0.1531 & 4.3 & 8.6 \\
$\begin{array}{c}\mathrm{Ht} \mathrm{NH}_{0.2 \mathrm{POS}} \\
\text { washed at } 50^{\circ} \mathrm{C}\end{array}$ & 0.770 & 0.1530 & 4.8 & 8.8 \\
$\mathrm{Ht}^{\mathrm{NH} 3}{ }_{0.2 \mathrm{POS} \text { washed at } 80^{\circ} \mathrm{C}}$ & 0.773 & 0.1531 & 5.6 & 10.2 \\
\hline
\end{tabular}

A visible effect of washing, beside the disappearance of reflexes belonging to $\mathrm{NH}_{4} \mathrm{NO}_{3}$ impurity, was a shift of basal reflection from $0.897 \mathrm{~nm}$ characteristic of the as received sample, to $0.769-0.773 \mathrm{~nm}$ observed in washed materials, which points to the replacement of interlayer nitrates with carbonate anions. The effect was attributed to the presence of $\mathrm{CO}_{2}$ dissolved in the distilled water and extended contact of the slurries with air during washing/centrifugation cycles. Moreover, it was obvious that washing with water induced a rapid recrystallization of the as received Ht sample. A pronounced effect is visible already after washing carried out at $0^{\circ} \mathrm{C}$, and crystal size grows further with increase of the washing temperature. Thus, if washing with water is required, the use of ice-cold water is advised to minimize recrystallization.

It is of interest whether the effect brought about by starch consists only in providing a biopolymer framework preventing nanoparticles clustering, or there exists a stronger interaction between the template and the precipitated solid. To shed more light on this aspect of starch/Ht composite formation, the materials were subjected to FTIR analysis.

Figure 5 a shows the spectra in middle infrared range of $\mathrm{Ht}^{\mathrm{NH} 3}{ }_{0.2 \mathrm{POS}}$ material, $\mathrm{Ht}^{\mathrm{NH} 3}$ reference prepared without starch, and dried $0.2 \mathrm{wt}$ \% gelatinized aqueous solution of starch used in the syntheses. The spectra of hydrotalcite phases are characteristic of these materials, with absorptions in the $3000-4000 \mathrm{~cm}^{-1}$ range due to the stretching vibrations of $\mathrm{OH}$ groups of the brucite-like sheets and in 
interlayer and/or adsorbed water, in the 1200-1800 $\mathrm{cm}^{-1}$ range due to interlayer anions and water, and below $1200 \mathrm{~cm}^{-1}$ due to lattice skeleton modes and low frequency bands of the interlayer anions [35]. The spectra confirmed the conclusion, drawn from the analysis of XRD patterns, that the $\mathrm{Ht}^{\mathrm{NH} 3}{ }_{0.2 \mathrm{POS}}$ sample contained predominantly nitrates in the interlayer, while $\mathrm{Ht}^{\mathrm{NH} 3}$ was intercalated chiefly by carbonates. FTIR spectrum of the former shows a $1385 \mathrm{~cm}^{-1}$ maximum characteristic of asymmetric stretching mode in nitrate anions, while the $1375 \mathrm{~cm}^{-1}$ absorption, dominating the spectrum of $\mathrm{Ht}^{\mathrm{NH} 3}$, was due to the asymmetric stretch in carbonates. The FTIR spectrum of dried starch gel shows bands due to $\mathrm{OH}$ stretches in water $\left(3000-4000 \mathrm{~cm}^{-1}\right), \mathrm{C}-\mathrm{H}$ stretching $\left(2800-3000 \mathrm{~cm}^{-1}\right)$, water scission and rocking vibrations (2000-2200 $\left.\mathrm{cm}^{-1}\right)$, water bending modes $\left(1600-1700 \mathrm{~cm}^{-1}\right), \mathrm{C}-\mathrm{O}, \mathrm{C}-\mathrm{C}, \mathrm{C}-\mathrm{OH}$ stretching (1100-1150 $\left.\mathrm{cm}^{-1}\right)$ and $\mathrm{C}-\mathrm{O}-\mathrm{H}$ bending $\left(900-1100 \mathrm{~cm}^{-1}\right)$ [38]. The latter region is referred to as a fingerprint one, because relative intensities of bands at 1045,1022 and $1000 \mathrm{~cm}^{-1}$ have been shown to be sensitive to structural changes in starch. In particular, in amorphous starch the band at 1022 $\mathrm{cm}^{-1}$ tended to be more pronounced than the other two, while the $1045 \mathrm{and} / \mathrm{or} 1000 \mathrm{~cm}^{-1}$ gained on intensity in ordered starch samples. This section of FTIR spectra, marked in Figure 5a, was blown up in Figure 5b. It may be seen that dried potato starch gel shows a poorly resolved spectrum dominated by the maximum at $1022 \mathrm{~cm}^{-1}$, in accordance with the loss of structural order occurring upon high temperature gelation. On the other hand, in the $\mathrm{Ht}^{\mathrm{NH} 3}{ }_{0.2 \mathrm{POS}}$ sample a clear increase of the intensity of the $1045 \mathrm{~cm}^{-1}$ band in relation to the $1022 \mathrm{~cm}^{-1}$ one was observed. Such an effect may be taken as an indication that upon interaction with hydrotalcite nanoparticles a degree of short range molecular order is regained by the starch gel adhering to the surface of precipitated Ht.

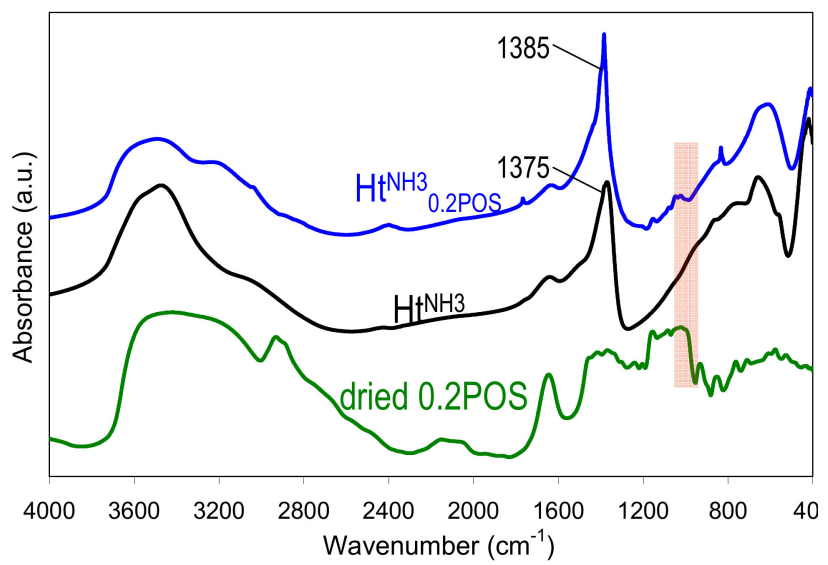

(a)

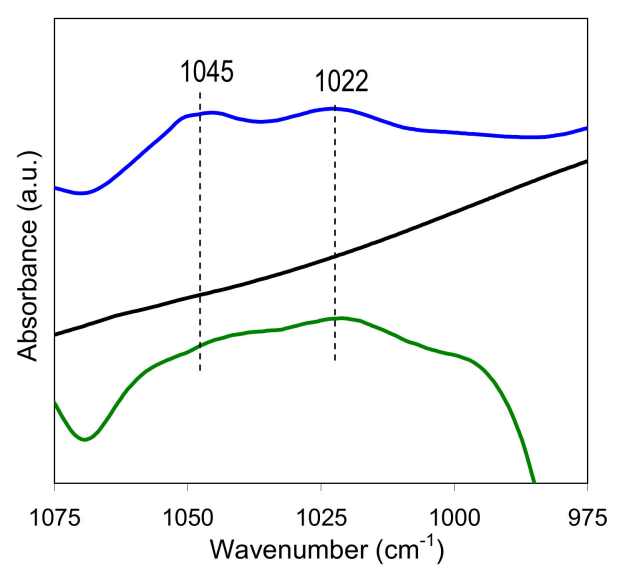

(b)

Figure 5. FTIR spectra of: (a) sample $\mathrm{Ht}^{\mathrm{NH} 3}{ }_{0.2 \mathrm{POS}}, \mathrm{Ht}^{\mathrm{NH}}$, and dried $0.2 \mathrm{wt}$. $\%$ potato starch gel, with the marked area indicative of starch order-disorder and the (b) blown-up fragment of the spectra in the marked area.

\section{Conclusions}

Results of the present study show that the synthesis of Ht materials in the presence of starch biotemplate, with use of the ammonia-based precipitant, enables preparation of nanocrystalline precipitates with very fine $(<50 \mathrm{~nm})$ particle size, comparable with those obtained by means of the inverse micellar route, but at much lower cost and with significantly less effort. Under the adopted experimental conditions all investigated types of starch had a similar effect on the crystallinity and the grain size of the Ht precipitates. Freeze-drying was the preferred method for achieving the possibly low Ht crystal size. Ht with the smallest nanocrystals was obtained when starch was present in all solutions used during synthesis. Synthesis in the presence of starch gel hindered incorporation of carbonate anions, and the layer charge was preferentially compensated by nitrates from a metal salts solution. Washing with water induced rapid recrystallization of the as received Ht materials and caused an exchange of nitrates with carbonates. If the washing step is required, the use of ice-cold 
water was advised to minimize recrystallization. The FTIR spectra show that an interaction existed between the biopolymer template and the Ht particles, resulting in a higher degree of order within the starch component adhering to Ht surface.

Author Contributions: A.M. synthesized the materials, B.D.N., A.W., J.K.C., D.D., performed the physico-chemical characterization experiments. All authors contributed to the interpretation of results, E.M.S. conceived and supervised the experiments, and prepared the manuscript. All authors have read and agreed to the published version of the manuscript.

Funding: This research was funded by the Polish National Science Center (NCN), grant OPUS, UMO-2017/27/B/ST5/01834.

Conflicts of Interest: The authors declare no conflict of interest. The funders had no role in the design of the study; in the collection, analyses, or interpretation of data; in the writing of the manuscript, or in the decision to publish the results.

\section{References}

1. Cavani, F.; Trifirò, F.; Vaccari, A. Hydrotalcite-type anionic clays: preparation, properties and applications. Catal. Today 1991, 11, 173-301. [CrossRef]

2. Del Hoyo, C. Layered double hydroxides and human health: An overview. Appl. Clay Sci. 2007, 36, $103-121$. [CrossRef]

3. Costa, F.R.; Saphiannikova, M.; Wagenknecht, U.; Heinrich, G. Layered Double Hydroxide Based Polymer Nanocomposites. In Wax Crystal Control Nanocomposites Stimuli-Responsive Polymers. Advances in Polymer Science; Springer: Berlin/Heidelberg, Germany, 2008; Volume 210, pp. 101-168.

4. Rives, V.; del Arco, M.; Martín, C. Layered double hydroxides as drug carriers and for controlled release of non-steroidal antiinflammatory drugs (NSAIDs): A review. J. Control. Release 2013, 169, 28-39. [CrossRef]

5. Mohapatra, L.; Parida, K. A review on the recent progress, challenges and perspective of layered double hydroxides as promising photocatalysts. J. Mater. Chem. A 2016, 4, 10744-10766. [CrossRef]

6. Takehira, K. Recent development of layered double hydroxide-derived catalysts - Rehydration, reconstitution, and supporting, aiming at commercial application. Appl. Clay Sci. 2017, 136, 112-141. [CrossRef]

7. Prevot, V.; Tokudome, Y. 3D hierarchical and porous layered double hydroxide structures: An overview of synthesis methods and applications. J. Mater. Sci. 2017, 52, 11229-11250. [CrossRef]

8. Ötvös, S.B.; Pálinkó, I.; Fülöp, F. Catalytic use of layered materials for fine chemical syntheses. Catal. Sci. Technol. 2019, 9, 47-60. [CrossRef]

9. Yang, Z.; Wei, J.; Zeng, G.; Zhang, H.; Tan, X.; Tan, X.; Ma, C.; Li, X.; Li, Z.; Zhang, C. A review on strategies to LDH-based materials to improve adsorption capacity and photoreduction efficiency for $\mathrm{CO}_{2}$. Coord. Chem. Rev. 2019, 386, 154-182. [CrossRef]

10. Zhao, Y.; Wei, M.; Lu, J.; Wang, Z.L.; Duan, X. Biotemplated hierarchical nanostructure of layered double hydroxides with improved photocatalysis performance. ACS Nano 2009, 3, 4009-4016. [CrossRef] [PubMed]

11. Zhang, T.; Zhou, Y.; Bu, X.; Xue, J.; Hu, J.; Wang, Y.; Zhang, M. Bio-inspired fabrication of hierarchically porous $\mathrm{Mg}-\mathrm{Al}$ composites for enhanced BSA adsorption properties. Micropor. Mesopor. Mater. 2014, 188, 37-45. [CrossRef]

12. Zhang, T.; Mei, Y.; Zhou, Z.; Bu, X.; Wang, Y.; Li, Q.; Yang, X. Template-controlled fabrication of hierarchical porous $\mathrm{Zn}-\mathrm{Al}$ composites with tunable micro/nanostructures and chemical compositions. Cryst. Eng. Comm. 2014, 16, 1793-1801. [CrossRef]

13. Li, J.; Zhang, N.; Ng, D.H.L. Synthesis of a 3D hierarchical structure of $\gamma-\mathrm{AlO}(\mathrm{OH}) / \mathrm{Mg}-\mathrm{Al}-\mathrm{LDH} / \mathrm{C}$ and its performance in organic dyes and antibiotics adsorption. J. Mater. Chem. A 2015, 3, 21106-21115. [CrossRef]

14. Gao, L.; Li, Q.; Hu, X.; Wang, X.; Song, H.; Yan, L.; Xiao, H. One-pot synthesis of biomorphic Mg-Al mixed metal oxides with enhanced methyl orange adsorption properties. Appl. Clay Sci. 2016, 126, 299-305. [CrossRef]

15. Wang, R.; Li, Q.; Duan, N.; Zhang, T.; Lu, H. Preparation of biomorphic Ni-Al LDHs using cotton from discarded T-shirt as a template and the adsorption capability for Congo red. Res. Chem. Intermed. 2015, 41, 7899-7914. [CrossRef] 
16. Wang, Y.; Li, Q.; Bo, L.; Wang, X.; Zhang, T.; Li, S.; Ren, P.; Wei, G. Synthesis and oil absorption of biomorphic $\mathrm{MgAl}$ layered double oxide/acrylic ester resin by suspension polymerization. Chem. Eng. J. 2016, 284, 989-994. [CrossRef]

17. Yu, J.; Lu, L.; Li, J.; Song, P. Biotemplated hierarchical porous-structure of $\mathrm{ZnAl-LDH} / \mathrm{ZnCo}_{2} \mathrm{O}_{4}$ composites with enhanced adsorption and photocatalytic performance. RSC Adv. 2016, 6, 12797-12808. [CrossRef]

18. Sobhana, S.S.L.; Bogati, D.R.; Reza, M.; Gustafsson, J.; Fardim, P. Cellulose biotemplates for layered double hydroxides networks. Micropor. Mesopor. Mater. 2016, 225, 66-73. [CrossRef]

19. Dong, J.; Zhu, T.; Li, H.; Sun, H.; Wang, Y.; Niu, L.; Wen, X.; Bai, G. Biotemplate-Assisted Synthesis of Layered Double Oxides Confining Ultrafine Ni Nanoparticles as a Stable Catalyst for Phenol Hydrogenation. Ind. Eng. Chem. Res. 2019, 58, 14688-14694. [CrossRef]

20. Coelho, A.; Perrone, O.M.; Gomes, E.; Da-Silva, R.; Thoméo, J.C.; Boscolo, M. Mixed metal oxides from sucrose and cornstarch templated hydrotalcite-like LDHs as catalysts for ethyl biodiesel synthesis. Appl. Catal. A 2017, 532, 32-39. [CrossRef]

21. Tao, X.; Liu, D.; Cong, W.; Huang, L. Controllable synthesis of starch-modified ZnMgAl-LDHs for adsorption property improvement. Appl. Surf. Sci. 2018, 457, 572-579. [CrossRef]

22. Ruiz-Hitzky, E.; Darder, M.; Aranda, P. Functional biopolymer nanocomposites based on layered solids. J. Mater. Chem. 2005, 15, 3650-3662. [CrossRef]

23. Zhang, G.; Shen, X.; Yang, Y. Facile synthesis of monodisperse porous ZnO spheres by a soluble starch-assisted method and their photocatalytic activity. J. Phys. Chem. C 2011, 115, 7145-7152. [CrossRef]

24. Ramimoghadam, D.; Hussein, M.Z.B.; Taufiq-Yap, Y.H. Hydrothermal synthesis of zinc oxide nanoparticles using rice as soft biotemplate. Chem. Cent. J. 2013, 7, 136. [CrossRef] [PubMed]

25. Ferreira, N.S.; Angélica, R.S.; Marques, V.B.; de Lima, C.C.O.; Silva, M.S. Cassava-starch-assisted sol-gel synthesis of $\mathrm{CeO}_{2}$ nanoparticles. Mater. Lett. 2016, 165, 139-142. [CrossRef]

26. Ramasami, A.K.; Reddy, M.V.; Nithyadharseni, M.V.P.; Vhowdari, B.V.R.; Balakrishna, G.R. Gel-combustion synthesized vanadium pentoxide nanowire clusters for rechargeable lithium batteries. J. Alloy. Compd. 2017, 695, 850-858. [CrossRef]

27. Hu, G.; Wang, N.; O'Hare, D.; Davis, J. Synthesis of magnesium aluminium layered double hydroxides in reverse microemulsions. J. Mater. Chem. 2007, 17, 2257-2266. [CrossRef]

28. Bellezza, F.; Cipiciani, A.; Costantino, U.; Nocchetti, M.; Posati, T. Hydrotalcite-like nanocrystals from water-in-oil microemulsions. Eur. J. Inorg. Chem. 2009, 18, 2603-2611. [CrossRef]

29. Napruszewska, B.D.; Michalik-Zym, A.; Dula, R.; Bielanska, E.; Rojek, W.; Machej, T.; Socha, R.P.; Lityńska-Dobrzyńska, L.; Bahranowski, K.; Serwicka, E.M. Composites derived from exfoliated Laponite and $\mathrm{Mn}-\mathrm{Al}$ hydrotalcite prepared in inverse microemulsion: A new strategy for design of robust VOCs combustion catalysts. Appl. Catal. B 2017, 211, 46-56. [CrossRef]

30. Napruszewska, B.D.; Michalik-Zym, A.; Rogowska, M.; Bielańska, E.; Rojek, W.; Gaweł, A.; Wójcik-Bania, M.; Bahranowski, K.; Serwicka, E.M. Novel Montmorillonite/TiO $2 / \mathrm{MnAl}$-Mixed Oxide Composites Prepared from Inverse Microemulsions as Combustion Catalysts. Materials 2017, 10, 1326. [CrossRef]

31. Smith, A.M. The biosynthesis of the starch granule. Biomacromolecules 2001, 2, 335-341. [CrossRef]

32. Creasey, J.J.; Chieregato, A.; Manayil, J.C.; Parlett, C.M.A.; Wilson, K.; Lee, A.F. Alkali- and nitrate-free synthesis of highly active $\mathrm{Mg}-\mathrm{Al}$ hydrotalcite-coated alumina for FAME production. Catal. Sci. Technol. 2014, 4, 861-870. [CrossRef]

33. Shen, J.; Kobe, J.M.; Chen, Y.; Dumesic, J.A. Synthesis and Surface Acid/Base Properties of Magnesium-Aluminum Mixed Oxides Obtained from Hydrotalcites. Langmuir 1994, 10, 3902-3908. [CrossRef]

34. Olszówka, J.E.; Karcz, R.; Bielańska, E.; Kryściak-Czerwenka, J.; Napruszewska, B.D.; Sulikowski, B.; Socha, R.P.; Gaweł, A.; Bahranowski, K.; Olejniczak, Z.; et al. New insight into the preferred valency of interlayer anions in hydrotalcite-like compounds: The effect of Mg/Al ratio. Appl. Clay Sci. 2018, 155, 84-94. [CrossRef]

35. Olanrewaju, J.; Newalkar, B.L.; Mancino, C.; Komarneni, S. Simplified synthesis of nitrate form of layered double hydroxide. Mater. Lett. 2000, 45, 307-310. [CrossRef]

36. Cantrell, D.G.; Gillie, L.J.; Lee, A.F.; Wilson, K. Structure-reactivity correlations in MgAl hydrotalcite catalysts for biodiesel synthesis. Appl. Catal. A: Gen. 2005, 287, 183-190. [CrossRef] 
37. Tittabut, T.; Trakarnpruk, W. Metal-Loaded MgAl Oxides for Transesterification of Glyceryl Tributyrate and Palm Oil. Ind. Eng. Chem. Res. 2008, 47, 2176-2181. [CrossRef]

38. Warren, F.J.; Gidley, M.J.; Flanagan, B.M. Infrared spectroscopy as a tool to characterise starch ordered structure - a joint FTIR-ATR, NMR, XRD, DSC study. Carbohydr. Polym. 2016, 139, 35-42. [CrossRef]

(C) 2020 by the authors. Licensee MDPI, Basel, Switzerland. This article is an open access article distributed under the terms and conditions of the Creative Commons Attribution (CC BY) license (http://creativecommons.org/licenses/by/4.0/). 